\title{
Critical Globalization Studies
}

\author{
William I. Robinson
}

If academics and intellectuals are to play a meaningful part in addressing the urgent issues that humanity faces in the twenty-first century-those of war and peace, social justice, democracy, cultural diversity, and ecological sustainability-it is incumbent upon us to gain an analytical understanding of globalization as the underlying structural dynamic that drives social, political, economic, and cultural processes around the world. My colleague Richard Appelbaum and I recently put out a call for a critical globalization studies (henceforth, CGS):

We believe that the dual objective of understanding globalization and engaging in global social activism can best be expressed in the idea of a critical globalization studies. We believe that as scholars it is incumbent upon us to explore the relevance of academic research to the burning political issues and social struggles of our epoch, to the many conflicts, hardships, and hopes bound up with globalization. More directly stated, we are not indifferent observers studying globalization as a sort of detached academic exercise. Rather, we are passionately concerned with the adverse impact of globalization on billions of people as well as our increasingly stressed planetary ecology. Moreover, we believe that it is our obligation as scholars to place an understanding of the multifaceted processes of globalization in the service of those individuals and organizations that are dedicated to fighting its harsh edges. We are not anti-globalists, but we are staunchly opposed to the highly predatory forms that globalization has assumed throughout history, and particularly during the past quarter century. (Appelbaum and Robinson, 2005: xiii)

In the present chapter I want to reiterate-and expand on-this call for a CGS. But I am concerned here as well with a related question: What is the 
role and responsibility of intellectual labor in global society? In what ways do we-or ought we to-participate in the public life of the new global society taking shape?

I believe that all intellectual labor is organic, in the sense that studying the world is itself a social act, committed by agents with a definite relationship to the social order. The role of intellectuals in society is, of course, a very old and recurrent theme. To talk of public sociologies today is to underscore both the social role and responsibility of intellectuals and academics. Scholars are indeed public intellectuals, whether or not we identify ourselves as such. By teaching, publishing, and participating in the administration of our universities and other social institutions, we engage in forms of social communication that influence the development of public consciousness, public understanding of social processes and political life, appraisals of the purpose and potential of social action, and imageries of alternative futures.

But there is more to the intellectual enterprise than this. Intellectual production is always a collective process. By collective I do not just mean collaborative projects among scholars or ongoing research programs. I want to foreground here the social and the historical character of intellectual labor. All those who engage in intellectual labor or make knowledge claims are organic intellectuals in the sense that all such labor is social labor, its practitioners are social actors, and the products of its labor are not neutral or disinterested. We must ask ourselves, what is the relationship between our intellectual work and power? What is the relationship between our research into globalization, and power in global society? To what ends and whose interests does our intellectual production serve? In short, as academics and researchers examining globalization, we must ask ourselves, whose mandarins are we?

We are living in troubling times. The system of global capitalism that now engulfs the entire planet is in crisis. There is consensus among scientists that we are on the precipice of ecological holocaust, including the mass extinction of species; the impending collapse of agriculture in major producing areas; the meltdown of polar ice caps; global warming; and the contamination of the oceans, the food stock, water supply, and air. Social inequalities have spiraled out of control and the gap between the global rich and the global poor has never been as acute as it is in the early twenty-first century. While absolute levels of poverty and misery expand around the world under a new global social apartheid, the richest 20 percent of humanity received in 2000 more than 85 percent of the world's wealth, while the remaining 80 percent had to make do with less than 15 percent, according to the United Nation's oft-cited annual Human Development Report (UNDP, 2001). Driven by the imperatives of overaccumulation and transnational social control, global elites have 
increasingly turned to authoritarianism, militarization, and war to sustain the system. Many political economists concur that a global economic collapse is possible, even probable.

In times such as these intellectuals much chose between legitimating the prevailing social order and providing technical solutions to the problems that arise in its maintenance, or exposing contradictions in order to reveal how they may be resolved by transcending the existing order. How do we address the crisis of global capitalism, clearly a crisis of civilizational proportions? While I cannot provide the answer, my contention here is that solutions require a critical analytical and theoretical understanding of global society, which is the first task of a CGS.

\section{GLOBAL CAPITALISM}

The task of a CGS is certainly daunting, given such a vast and complex theoretical object as emergent global society, and the character of the current situation as transitionary and not accomplished. Globalization in my analysis is a qualitatively new stage in the history of world capitalism (Robinson, 2004). If earlier stages brought us colonial conquest, a world economy, and an international division of labor, the partition of the world into North and South, and rising material prosperity amidst pauperization, this new era is bringing us into a singular global civilization, in which humanity is bound together as never before, yet divided into the haves and the have-nots across national and regional borders in a way unprecedented in human history. This new transnational order dates back to the world economic crisis of the 1970s and took shape in the 1980s and 1990s. It is marked, in my analysis, by a number of fundamental shifts in the capitalist system. These shifts include, first, the rise of truly transnational capital and the integration of every country into a new global production and financial system. The era of the primitive accumulation of capital is coming to an end as commodification penetrates every nook and cranny of the globe and invades public and community spheres previously outside its reach. In this process millions have been wrenched from the means of production, proletarianized, and thrown into a (gendered and racialized) global labor market that transnational capital has been able to shape.

Second is the appearance of a new transnational capitalist class (TCC), a class group grounded in new global markets and circuits of accumulation, rather than national markets and circuits. In every country of the world, a portion of the national elite has become integrated into this new transnationally oriented elite. Global class formation has also involved the rise of a new global working class - a labor force for the new global production system- 
yet stratified less along national than along social lines in a transnational environment. Third is the rise of a transnational state (TNS), a loose but increasingly coherent network comprised of supranational political and economic institutions, and of national state apparatuses that have been penetrated and transformed by the TCC and allied transnationally oriented bureaucratic and other strata. Once captured by such forces, national states tend to become components of a larger TNS that serves the interests of global over national or local accumulation processes. The TNS has played a key role in imposing the neoliberal model on the Global South. It has advanced the interests of transnational capitalists and their allies over nationally oriented groups among the elite, not to mention over workers and the poor. National states become wracked by internal conflicts that reflect the contradictions of the larger global system.

Fourth is the appearance of novel relations of inequality in global society. As capitalism globalizes, the twenty-first century is witness to new forms of poverty and wealth, and new configurations of power and domination. Global capitalism has generated new social dependencies around the world. Billions of people have been brought squarely into the system, whereas before they may have been at the margins or entirely outside of it. The system is very much a life-and-death matter for billions of people who, willing or otherwise, have developed a stake in its maintenance. Indeed, global capitalism is hegemonic not just because its ideology has become dominant but also, and perhaps primarily, because it has the ability to provide material rewards and to impose sanctions.

Globalization is anything but a neutral process. It has produced winners and losers, and therefore has its defenders and opponents. There is a new configuration of global power that becomes manifest in each nation and whose tentacles reach all the way down to the community level. Each individual, each nation, and each region is being drawn into transnational processes that have undermined the earlier autonomies and provincialisms. This makes it entirely impossible to address local issues removed from global context. At the same time, resistance has been spreading throughout global society. There are burgeoning social movements of workers and the poor, transnational feminism, indigenous struggles, demands for human rights and democratization, and so on.

Where do scholars and academics fit in all of this? Where ought they fit in? Universities are centers for the production and reproduction of knowledge and culture. As all social institutions, they internalize the power relations of the larger society to which they belong. Over the past decades, and in tandem with the spread of capitalist globalization, we have witnessed relentless pressures worldwide to commodify higher education, the increasing privatization 
of universities and their penetration by transnational corporate capital. If the university is to pull back from such a course it must fulfill a larger social function in the interests of broad publics and from the vantage point of a social logic that is inevitably at odds with the corporate logic of global capitalism.

\section{EXERCISING A "PREFERENTIAL OPTION" FOR THE SUBORDINATE MAJORITY OF GLOBAL SOCIETY}

In the 1960s and 1970s in Latin America and elsewhere, lay people and grassroots clerics from the Catholic Church questioned the precepts of the prevailing dogma and turned to constructing a church of the poor under the banner of liberation theology. These leaders of the popular church had begun working in social and self-help projects in the countryside and among impoverished urban neighborhoods. They soon realized, however, that a narrow self-improvement outlook was insufficient in the face of glaring injustices and entrenched power structures. Liberation theology called for Christians to exercise a "preferential option for the poor" in their social and evangelical work.

What the popular church recognized in the 1960s and 1970s for the Catholic Church-namely, that it is part of a larger society, reflects the divisions, struggles, and power relations of that society, and that members of the church are not neutral in the face of the battles that rage in society-holds true for the university. I want to call for scholars and intellectuals in the twenty-first century to exercise a preferential option for subordinate majorities of emergent global society.

What does it mean to exercise a preferential option for the majority in global society? In my view, what is required in global society, seen from the needs and aspirations of the poor majority of humanity, for whom global capitalism is nothing short of alienation, savagery, and dehumanization, are organic intellectuals capable of theorizing the changes that have taken place in the system of capitalism, in this epoch of globalization, and of providing to popular majorities these theoretical insights as inputs for their real-world struggles to develop alternative social relationships and an alternative social logic - the logic of majorities - to those of the market and of transnational capital. In other words, a critical globalization studies has to be capable of inspiring emancipatory action, of bringing together multiple publics in developing programs that integrate theory and practice.

This does not mean that practicing a CGS is reduced to running out and joining mass movements. It is, to be sure, a good idea to do so, although 
academics must be careful not to impose their "knowledge power" on these movements. Great scholars throughout the ages, those that have truly had an impact on history, have also been social activists and political agents. But the key thing here is to bring our intellectual labor-our theorizing and systematic research - to bear on the crisis of humanity. This involves critical thinking. The distinction between critical and noncritical ways of thinking is what Max Horkheimer (1972) first called "traditional" versus "critical" thinking, and what Robert Cox (1995) more recently has referred to as "problem solving" versus "critical" thinking. The critical tradition in the social sciences, not to be confused with the related but distinct critical theory as first developed by the Frankfurt School in Western Marxist thought, refers in the broadest sense to those approaches that take a critical view of the prevailing status quo and explicitly seek to replace the predominant power structures and social hierarchies with what are seen as more just and equitable social arrangements. Critical thinking therefore cannot take place without linking theory to practice, without a theoretically informed practice. Praxis is at the core of a CGS.

Does such a CGS imply that scholarship and the academic profession become comprised by "politicizing" them in this way? There is no value-free research, and there are no apolitical intellectuals. (This is not to say that our research should not adhere to the social science rules of logic and empirical verification; indeed it must be lest it is reduced to propaganda.) We know from the philosophy and the sociology of knowledge that knowledge is never neutral or divorced from the historic context of its production, including from competing social interests (see, inter alia, Therborn, 1985; Fray, 1987; Chalmers, 2000; Sartre 1974; Robinson, 1996). Intellectual production always parallels, and can be functionally associated with, movement and change in society. There is no such thing as an intellectual or an academic divorced from social aims that drive research, not in the hard sciences, and much less in the social sciences and humanities. The mainstream scholar may "well believe in an independent, 'suprasocial,' detached knowledge as in the social importance of his expertise," observes Horkheimer. "The dualism of thought and being, understanding and perception is second nature to the scientist.... [such mainstream scholars] believe they are acting according to personal determinations, whereas in fact even in their most complicated calculations they but exemplify the working of an incalculable social mechanism" (1972: 196-97).

Many "mainstream" academics, shielded by the assumptions of positivist epistemologies, would no doubt take issue with this characterization of intellectual labor as, by definition, a social act by organic social agents. There are those who would posit a free-floating academic, a neutral generator of 
knowledge and ideas. But few would disagree that scholars and intellectuals are knowledge producers and that "knowledge is power." Hence it is incumbent on us to ask, Power for whom? Power exercised by whom? Power to what ends? The theoretical and research trajectories of social scientists, policy makers, and others within the academic division of labor are influenced by their social position as shaped by class, as well as by gender, race, and culture. But many academics are linked to the state, to other social institutions, and to dominant groups in a myriad of ways, from corporate and state funding of research, to status, prestige, job security, and social approval that comes from integration into the hegemonic order, in contrast, as Ollman shows, to the well-known sanctions one risks in committing to a counterhegemonic project (1976: 119-32).

Academics who believe they can remain aloof in the face of the conflicts that are swirling about us and the ever-higher stakes involved are engaged in a self-deception that is itself a political act. The claim to nonpolitical intellectual labor, value neutrality, and so forth, is part of the very mystification of knowledge production and the ideological legitimation by intellectual agents of the dominant social order. Such intellectuals, to quote Sartre following Gramsci, are "specialists in research and servitors of hegemony" (1974: 238). The prevailing global order has its share of intellectual defenders, academics, pundits, and ideologues. These "functionaries of the superstructure" (Sartre, 1974: 238) serve to mystify the real inner workings of the emerging order and the social interests embedded therein. They become central cogs in the system of global capitalism, performing not only legitimating functions but also developing practical and particularist knowledge intended to provide technical solutions in response to the problems and contradictions of the system. In short, whether intended or not, they exercise a "preferential option" for a minority of the privileged and the powerful in global capitalist society.

The mood in academia, especially in the United States, generally trails behind and reflects that of the political and social climate. At times of rising popular and mass struggles, when counterhegemonic forces are coalescing, the academy can become radicalized. At times of conservative retrenchment the academy retreats, and those playing a major role in intellectual legitimation of the state of affairs (and the affairs of the state) move more on the offensive and academic repression can set in. If the 1960s and 1970s saw a radicalization of the university in the United States and elsewhere, then the 1980s and 1990s saw a conservative counteroffensive. In the 1980s and onwards we have witnessed, in tandem with the onslaught of neoliberalism and capitalist globalization, the privatization of higher education (and increasingly of secondary education), the rise of neoliberal private universities, the defunding of the public academy, the unprecedented penetration- 
often takeover-of universities by transnational corporate capital, and the ever greater commodification of education.

\section{SEVERAL INTERWOVEN TENETS OF A CRITICAL GLOBALIZATION STUDIES}

\section{Reflexivity and History}

Critical theory, in the view of one well-known nineteenth-century social thinker, is "the self-clarification of the struggles and wishes of the age" (Marx, as cited in Fraser, 1987: 31). A CGS must be concerned with reflexivity and with history, such that it does not take for granted the prevailing power structures, but rather problematizes and historicizes existing arrangements and established institutions. A critical studies can only mean that we do not accept the world as we find it as being in any sense natural. Hence the first step in any CGS is to problematize the social reality that we study and in which we exist, to acknowledge that the society in which we live is only one possible form of society and that as collective agents we make and remake the world even if, as Marx famously admonished, under conditions not of our own choosing. If we acknowledge the historical specificity of existing social arrangements, then we cannot engage in a critical studies without identifying and foregrounding the nature of the particular historical society in which we live, which for us is global capitalist society.

Once we ask, what is the beginning-and how may we imagine the end-of the existing order of things, then the next question a critical studies must ask is, What are the collective agents at work? What are the real and potential human agencies involved in social change? What is their relationship to the prevailing order and to one another? Among the myriad of multilayered social forces in struggle, in analytical abstraction and simplified terms, there are those that seek to reorganize and reconstruct on new bases these arrangements, that is to say, struggles for social emancipation, and there are those that seek to defend or sustain these arrangements. We want to acknowledge struggles from below and struggles from above and focus our analytical attention on the interplay between them.

\section{A Global Perspective}

A CGS must take a global perspective, in that social arrangements in the twenty-first century can only be understood in the context of global-level structures and processes, that is to say, in the context of globalization. This is the "think globally" part of the oft-cited aphorism "think globally, act 
locally." The perceived problematics of the local and of the nation-state must be located within a broader web of interconnected histories that in the current era are converging in new ways. Any critical studies in the twenty-first century must be, of necessity, also a globalization studies.

But global-level thinking is a necessary but not sufficient condition for a critical understanding of the world. Transnational corporate and political elites certainly have a global perspective. Global thinking is not necessarily critical and is just as necessary for the maintenance of global capitalism as critical global-level thinking is for emancipatory change. If we can conceptualize a CGS then we should be able to conceive of a "noncritical globalization studies." If a CGS is one that acknowledges the historical specificity of existing social arrangements, then a "noncritical globalization studies" is one that takes the existing world as it is. Such a non-critical globalization studies is thriving in the twenty-first-century academy. It is a studies that denies that the world we live in-twenty-first-century global society-is but one particular historical form, one that has a beginning and an end, as do all historical forms and institutions.

\section{The Subversive Nature of a CGS}

In the tradition of critical studies, a CGS is subversive insofar as it explicitly seeks to replace predominant power structures and social hierarchies with what are seen as more just and equitable social arrangements. A CGS involves exposing the ideological content of theories and knowledge claims often put forward as social scientific discourse, the vested interests before the façade of neutral scholarship, and how powerful institutions really work. This means challenging the dominant mythologies of our age, such as that ecologically sound development is possible under capitalism, that "democracy" exists where tiny minorities control wealth and power, or that we are moving toward an "ownership society" when in fact we live in a usurped society in which the lot of the majority is one of increasing dispossession. In this sense, a CGS is a counterhegemonic practice that seeks to rebuild public discourse by "speaking truth to power."

It involves making visible and unmasking power relations in our institutions and professional associations, in our locales and in the largerultimately global—society. While the substantive agenda of a CGS must be open, the underlying enterprise involves applying our training and experience to elucidating the real inner workings of the social order and the contradictions therein. This must include putting forward a cogent and systematic critique of global capitalism that exposes injustices, makes invisible problems visible, and reveals pressure points in the system. Rendering visible what 
Paul Farmer (2003) terms the "pathologies of power" means "bearing witness," but more than that it means showing how suffering is a consequence of the structural violence that is immanent to the prevailing system and that links together apparently disconnected aspects of that system. We should recall, in this regard, Sartre's admonition, in his "A Plea for Intellectuals," that "the exploited classes do not need an ideology so much as the practical truth of society; they need knowledge of the world in order to change it" (1974). As regards a CGS, we would do well to follow Susan George's advice to study not so much the oppressed as the powerful:

Those that genuinely want to help the movement should study the rich and powerful, not the poor and powerless. Although wealth and power are in a better position to hide their activities and are therefore more difficult to study, any knowledge about them will be valuable to the movement. The poor and powerless already know what is wrong with their lives and those who want to help them should analyze the forces that keep them poor and powerless. Better a sociology of the Pentagon or the Houston country club than of single mothers or L.A. gangs (2005: 8).

In the end, a CGS involves questioning everything, deconstructing everything, interrogating every claim to knowledge, yet it also means reconstructing what we have deconstructed and contributing to the construction of an alternative future.

\section{Engagement with Everyday Concerns}

To engage in a CGS means to maintain contact with everyday concerns, a connection with social forces from below, in its theoretical and empirical research concerns. Such engagement with everyday concerns is the "act locally" of the oft-cited aphorism. People experience global capitalism in their localities and everyday lives. For a CGS, the local-global link means identifying how global processes have penetrated and restructured localities in new ways, organically linking local realities to global processes. Burawoy et al. have shown in their diverse locally situated studies what they call a "global ethnography," how "ethnography's concern with concrete, lived experience can sharpen the abstractions of globalization theories into more precise and meaningful conceptual tools" (2000: xiv).

It is at this local, experienced level of global capitalism that intellectuals engage in active participation in everyday life, acting as agents or organizers, or in Gramsci's words, as "permanent persuaders" in the construction of hegemonic social orders (1971: 9-10). The intellectual in this case contributes to the active construction of hegemony by particular social forces that construct and maintain a social order on an ongoing basis. But such intellec- 
tual labor can also entail a connection with opposing initiatives, with forces from below and their attempts to forge a counterhegemony by drawing out the connections, through theoretical reflection, that link the distinct lived realities, everyday spontaneous and organized forms of struggle. By propagating certain ideas, intellectuals play an essential mediating function in the struggle for hegemony, Gramsci reminds us, by acting as "deputies" or instruments of hegemony, or by performing a valuable supporting role to subordinate groups engaged in promoting social change $(5-23 ; 52-55)$.

\section{CGS as Praxis}

As should be clear from all the above, a CGS is a praxis. (Indeed, the broader point that I am unable to elaborate on here is that all intellectual labor is praxis and for that reason organic. The question is, a theory-practice by whom, for whom, and to what end?) A CGS is grounded in the linkage of theory to practice, insofar as we cannot really know the world without participating in efforts to change it, which is the same as to say that it is only when we engage in collective efforts to change the world that we truly come to know the world. At the pedagogical level, the praxis of a CGS is a pedagogy of the oppressed, a process of conscientization, understood as learning to perceive social, political, and economic contradictions, and to take action against the oppressive elements of reality. A CGS must not only link intellectual production and knowledge claims to emancipatory projects. It must also enjoin discursive with material struggles, lest the latter become reduced to irrelevant word games.

To reiterate, the praxis of a CGS implies bringing the intellectual labor of social scientists-our theoretical work and systematic research-to bear on the crisis of humanity. Universities, think tanks, and NGOs must be bastions of critique of the

twenty-first-century global order, incubators for critical thinking, and reservoirs for debate, alternative ideas, and counterhegemonies. A CGS must be capable of contributing in this way to the development of programs that integrate theory with practice and the local with the global, of inspiring emancipatory action. A CGS is not satisfied with "the art of the possible"; its labor aims to help us move beyond the limits of the possible.

\section{EPISTEMOLOGICAL “GROUND RULES" OF A CGS}

There are certain "epistemological ground rules" for "doing a CGS," including a transdisciplinary, holistic, and dialectical approach that focuses on sys- 
temic connections that underlie the various aspects of the social-in this case, global-reality it studies. A CGS should be an open space, broad enough to house a diversity of approaches and epistemologies, from Marxist to radical variants of institutional, Weberian, feminist, poststructural, and other traditions in critical thought, and should as well emphasize including questions of contingency, culture, and subjectivity. But, to reiterate, what distinguishes (or must distinguish) a CGS from a noncritical globalization studies is reflexivity, a critical global perspective, the subversive nature of its thought in relation to the status quo, and a praxis as theoretically informed practice.

A CGS is, by definition, interdisciplinary-or more accurately, transdisciplinary. It is holistic in conception and epistemology, which is not to say, as a matter of course, that particular studies necessarily take the "whole" as the object of inquiry. As Palan has noted, "the broadly critical tradition in the social sciences is naturally attracted to holistic interpretations of social relations ... The assumption being that there are totalizing processes driven by a predominant logic which we call capitalism, and that such totalizing processes manifest themselves in all aspects of social life" (2000: 16). The critical tradition maintains therefore that there is no point in studying each facet of social life as an independent system of relationships-for the simple reason that they are not independent but interdependent, as internally related elements of a more encompassing totality. Consequently, the critical tradition does not accept the analytical legitimacy of formal academic divisions.

This does not mean that there is any single "right" way to engage in a critical globalization studies. I would insist, nonetheless, that it is not possible to understand global society in the absence of a political economy analysis. Political economy historically has concentrated on the analytical as well as prescriptive questions of how order and change come about. The history of the breakup in the nineteenth and twentieth centuries of political economy into artificial and compartmentalized "disciplines" is well known (Blackburn, 1972; Wallerstein, 2001; Therborn, 1985). We need to recapture the critical essence of political economy, which takes as its basis the production and reproduction of our material existence, and on that basis seeks to ask how change can be brought about, by whom, and for whom.

Yet it is equally true that the manifold dimensions of the social totality cannot be reduced to epiphenomena of the material bases of global society. Such an approach would not be dialectical-that is, holistic - but mechanical and misleading. The opposition of political economy to cultural analysis, for instance, is a false dualism that obscures rather than elucidates the complex reality of global society, insofar as our material existence as humans is always, of necessity, only possible through the construction of a symbolic order and systems of meaning that are themselves the products of historically 
situated social forces and have an ongoing recursive effect on material reality. Indeed, as Raymond Williams, among others, has constantly reminded us, culture is itself a material force.

A CGS therefore requires dialectical thought at the level of epistemology, as a way of knowing. In epistemological terms, dialectics means a dialogue seeking truth through exploration of contradictions and through identifying the internal relations that bind together diverse and multifaceted dimensions of social reality into an open totality. In the dialectical approach the different dimensions of our social reality do not have an "independent" status insofar as each aspect of reality is constituted by, and is constitutive of, a larger whole of which it is an internal element. An internal relation is one in which each part is constituted in its relation to the other, so that one cannot exist without the other and only has meaning when seen within the relation, whereas an external relation is one in which each part has an existence independent of its relation to the other (Ollman, 1976). Viewing things as externally related to each other inevitably leads to dualist constructs and false dichotomies (e.g., political economy versus culture, the local/national and the global). The distinct levels of social structure-in this case, global social structure - cannot be understood independent of each other, but neither are these levels reducible to any one category. They are internally related, meaning that they can only be understood in their relation to each other and to the larger social whole.

Critical thought, in this regard, means applying a dialectical as opposed to a formal logic, one that focuses not on things in themselves but on the interrelations among them. A dialectical logic involves identifying how distinct dimensions of social reality may be analytically distinct (such as the three most salient axes of social inequality—race, class, and gender) yet are mutually constitutive of each other as internal elements of a more encompassing process. Our task is to uncover internal linkages among distinct sets of historical relationships and their grounding in an underlying (that is, more primary) historic process, which in my view are material relations of production and reproduction and the historical ordering principle those relations put forth. This is to argue that historical processes of production and reproduction are causal processes. To take the case of race and class, it is not that racialization processes occurring around the world in the twenty-first century can be explained in terms of class but that class itself became racialized in the formative years of the world capitalist system because of the particular history of that system. I will not draw out the point further here. Suffice it to note that ultimately we are concerned here with the dialectical relationship between consciousness and being.

Twenty-first-century global society is characterized by a far greater com- 
plexity and much faster change and interaction than at any time in human history. It is only possible to grasp both the complexity of these structures and processes, and the dynamics of change, through a dialectical approach. For Ollman, the dialectic method involves six successive moments. The ontological moment has to do with the infinite number of mutually dependent processes that make up the totality, or structured whole, of social life. The epistemological moment deals with how to organize thinking in order to understand such a world, abstracting out the main patterns of change and interaction. The moment of inquiry appropriates the patterns of these internal relationships in order to further the project of investigation. The moment of intellectual reconstruction or self-clarification puts together the results of such an investigation for oneself. The moment of exposition entails describing to a particular audience the dialectical grasp of the facts by taking into account how others think. Finally, the moment of praxis uses the clarification of the facts of social life to act consciously in and on the world, changing it while simultaneously deepening one's understanding of it (Ollman, 1998: 342). Applied to the matter before us, we could say that, through social engagement, active theorizing, and political work, a critical globalization studies becomes self-knowledge of global society.

\section{CONCLUSION}

With the apparent triumph of global capitalism in the 1990s, following the collapse of the old Soviet bloc, the defeat of Third World nationalist and revolutionary projects, and the withdrawal of the Left into postmodern identity politics and other forms of accommodation with the prevailing social order, many intellectuals who previously identified with resistance movements and emancipatory projects seemed to cede a certain defeatism before global capitalism. Such defeatism has no place in a CGS. The decline of the Left and socialist movements worldwide, a result, among other factors, of the chronic gap between theory and practice, thought and action, led to a degeneration of intellectual criticism as well. An embrace of the "End of History" thesis (Fukuyama, 1992) is the end not of history but of critical thought.

The current epoch is a time of rapidly growing global social polarization between a shrinking majority of haves and an expanding minority of havenots. It is a time of escalating political and military conflict as contending social forces face each other in innumerable yet interwoven struggles around the world. The global capitalist system faced by the turn of the century a structural crisis of overaccumulation and also an expanding crisis of legitimacy in the face of the "irresistible" rise of a global justice movement (Notes 
from Nowhere, 2003). There was certainly no wanting of mass mobilization and political protagonism from below before which a CGS could contribute much.

\section{ACKNOWLEDGMENTS}

I would like to thank Jackie Smith, John Foran, Richard Appelbaum, and Keri Iyall Smith for comments and suggestions on earlier versions of this chapter.

\section{REFERENCES}

Applebaum, Richard P., and William I. Robinson (eds.). Critical Globalization Studies. New York: Routledge, 2005.

Blackburn, Robin, ed. 1972. Ideology in Social Science: Readings in Critical Social Theory. Suffolk, UK: Fontana/Collins.

Burawoy, Michael, Joseph A. Blum, Sheba George, Zsuzsa Gille, Teresa Gowan, Lynne Haney, Maren Klawiter, Steven H. Lopez, Sean O Riain, and Millie Thayer. 2000. Global Ethnography: Forces, Connections, and Imaginations in a Postmodern World. Berkeley: University of California Press.

Chalmers, Alan, F. 2000. What Is This Thing Called Science? 3rd ed. Indianapolis: Hackett Publishing Co.

Cox, Robert, W. 1995. "Critical Political Economy." In International Political Economy: Understanding Global Disorder, ed. Bjorne Hettne, 31-45. London: Zed.

Farmer, Paul. 2003. Pathologies of Power: Health, Human Rights, and the New War on the Poor. Berkeley: University of California Press.

Fraser, Nancy. 1987. "What's Critical about Critical Theory? The Case of Habermas and Gender." In Feminism as Critique: On the Politics of Gender, ed. Seyla Benhabib and Drucilla Cornell, 31-56. Minneapolis: University of Minnesota Press.

Fray, Brian. 1987. Critical Social Science. Cambridge: Polity Press.

Fukuyama, Francis. 1992. The End of History and the Last Man. London: Penguin.

George, Susan. 2005. "If You Want to Be Relevant: Advice to the Academic from a Scholar-Activist." In Critical Globalization Studies, ed. Richard P. Applebaum, and William I. Robinson. New York: Routledge, 2005.

Gramsci, Antonio. 1971. Selections from the Prison Notebooks. New York: International Publishers.

Horkheimer, Max. 1972. "Traditional and Critical Theory." In Critical Theory: Selected Essays, trans. Matthew J. O'Connell, 188-243. Toronto: Herder and Herder.

Notes from Nowhere. 2003. We Are Everywhere: The Irresistible Rise of Global Anticapitalism. London: Verso.

Ollman, Bertell. 1998. "Why Dialectics? Why Now?" Science and Society 62(3): 339-57.

- 1976. Alienation. 2nd ed. Cambridge: Cambridge University Press.

Palan, Ronen. 2000. "New Trends in Global Political Economy." In Global Political Economy: Contemporary Theories, ed. Ronen Palan, 1-18. London: Routledge. 
Robinson, William, I. 2004. A Theory of Global Capitalism: Production, Class, and State in a Transnational World. Baltimore, Md.: Johns Hopkins University Press.

1996. Promoting Polyarchy: Globalization, U.S. Intervention, and Hegemony. Cambridge: Cambridge University Press.

Sartre, Jean-Paul. 1974. "A Plea for Intellectuals." In Between Existentialism and Marxism. London: New Left Books.

Therborn, Goran. 1985. Science, Class \& Society: On the Formation of Sociology \& Historical Materialism. London: Routledge.

United Nations Development Program. 2001. Human Development Report. New York: United Nations/Oxford University Press.

Wallerstein, Immanuel. 2001. Unthinking Social Science: The Limits of 19th Century Paradigms. Philadelphia: Temple University Press. 